\title{
Infant feeding patterns in families with a diabetes history - observations from The Environmental Determinants of Diabetes in the Young (TEDDY) birth cohort study
}

\author{
Sandra Hummel ${ }^{1,2, *}$, Kendra Vehik ${ }^{3}$, Ulla Uusitalo ${ }^{3}$, Wendy McLeod $^{3}$, \\ Carin Andrén Aronsson ${ }^{4}$, Nicole Frank ${ }^{5}$, Patricia Gesualdo 5 , Jimin Yang ${ }^{3}$, \\ Jill $M$ Norris $^{6}$, Suvi M Virtanen $7,8,9,10$ and the TEDDY Study Groupt \\ ${ }^{1}$ Institute of Diabetes Research, Helmholtz Zentrum München and Forschergruppe Diabetes, Klinikum rechts der \\ Isar, Technische Universität München, Ingolstaedter Landstrasse 1, D-85764 Neuherberg, Germany: \\ ${ }^{2}$ Forschergruppe Diabetes eV, Neuherberg, Germany: ${ }^{3}$ Morsani College of Medicine, Pediatrics Epidemiology \\ Center, University of South Florida, Tampa, FL, USA: ${ }^{4}$ Department of Clinical Sciences, Lund University, Malmo, \\ Sweden: ${ }^{5}$ The Barbara Davis Center for Childhood Diabetes, University of Colorado Denver, Aurora, CO, USA: \\ ${ }^{6}$ Colorado School of Public Health, University of Colorado, Aurora, CO, USA: ${ }^{7}$ Unit of Nutrition, National \\ Institute for Health and Welfare, Helsinki, Finland: ${ }^{8}$ School of Health Sciences, University of Tampere, Tampere, \\ Finland: ${ }^{9}$ Science Center of Pirkanmaa Hospital District, Tampere, Finland: ${ }^{10}$ Research Center for Child Health, \\ Tampere University and University Hospital, Tampere, Finland
}

Submitted 26 December 2012: Final revision received 13 September 2013: Accepted 15 0ctober 2013: First published online 27 November 2013

\begin{abstract}
Objective: To assess the association between diabetes family history and infant feeding patterns

Design: Data on breast-feeding duration and age at first introduction of cow's milk and gluten-containing cereals were collected in 3-month intervals during the first 24 months of life.

Setting: Data from the multicentre TEDDY (The Environmental Determinants of Diabetes in the Young) study, including centres in the USA, Sweden, Finland and Germany.

Subjects: A total of 7026 children, including children with a mother with type 1 diabetes (T1D; $n$ 292), gestational diabetes mellitus (GDM; $n$ 404) or without diabetes but with a father and/or sibling with T1D ( $n$ 464) and children without diabetes family history ( $n$ 5866).

Results: While exclusive breast-feeding ended earlier and cow's milk was introduced earlier in offspring of mothers with T1D and GDM, offspring of nondiabetic mothers but a father and/or sibling with T1D were exclusively breast-fed longer and introduced to cow's milk later compared with infants without diabetes family history. The association between maternal diabetes and shorter exclusive breast-feeding duration was attenuated after adjusting for clinical variables (delivery mode, gestational age, Apgar score and birth weight). Country-specific analyses revealed differences in these associations, with Sweden showing the strongest and Finland showing no association between maternal diabetes and breast-feeding duration.

Conclusions: Family history of diabetes is associated with infant feeding patterns; however, the associations clearly differ by country, indicating that cultural differences are important determinants of infant feeding behaviour. These findings need to be considered when developing strategies to improve feeding patterns in infants with a diabetes family history.
\end{abstract}

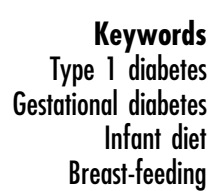

Breast-feeding provides numerous immunological, psychological, social, economic and environmental benefits, is a natural first food and an ideal nutrition for the infant ${ }^{(1)}$. Therefore the WHO expert consultation recommends

$\dagger$ Members of the TEDDY Study Group are listed in the Appendix full breast-feeding for 6 months, with introduction of complementary foods and continued breast-feeding thereafter $^{(2)}$. Nevertheless, the prevalence of exclusive breast-feeding for 6 months is low in most countries ${ }^{(3)}$ and various studies worldwide are aiming to identify predictors of short exclusive breast-feeding duration ${ }^{(4)}$. 
Both maternal type 1 diabetes (T1D) and gestational diabetes mellitus (GDM) have been associated with shorter breast-feeding duration ${ }^{(5-7)}$. This may be explained by factors that are associated with maternal diabetes, such as the increased frequency of caesarean sections and preterm delivery ${ }^{(8)}$. However, there have also been studies that did not find an association between maternal diabetes and breast-feeding duration ${ }^{(9,10)}$.

Little is known on the effect of maternal diabetes and a T1D family history on the timing of introduction of complementary food. Findings from the German BABYDIET study indicated that offspring of mothers with T1D are introduced to complementary foods earlier than offspring of fathers and/or siblings with T1D ${ }^{(11)}$.

In addition to the beneficial effects of exclusive breastfeeding on maternal and offspring health mentioned above, prospective studies in children at increased risk for T1D have suggested that the timing of initial exposure to complementary foods may influence the risk of islet autoimmunity and T1D. Among candidate risk factors for islet autoimmunity are early introduction to cow's milk and to solid foods such as gluten-containing cereals, fruits/berries and roots ${ }^{(12-15)}$. Based on these findings it is important to identify determinants of infant feeding patterns in children at increased risk for T1D.

Therefore the aim of the current analysis was to assess the association of maternal T1D or GDM and nonmaternal T1D in the family with infant feeding patterns. The patterns of interest in the present study were duration of exclusive and any breast-feeding and introduction ages of cow's milk and gluten-containing cereals (wheat, rye or barley). Breast-feeding duration and timing of introduction of complementary foods are strongly affected by countryspecific socio-cultural factors and dietary guidelines. The TEDDY (The Environmental Determinants of Diabetes in the Young) study, which is an international, multicentre birth cohort study with standardized recruitment, dietary collection methodologies and analytical approaches, offers the opportunity to stratify for country ${ }^{(16)}$.

\section{Patients and methods}

Information on early infant feeding practices was obtained for 7026 children participating in the prospective TEDDY birth cohort study, a multicentre study comprising six clinical centres located in the USA and Sweden, Finland and Germany with the aim of identifying environmental factors that may trigger islet autoimmunity and T1D in children at increased genetic risk for T1D ${ }^{(16)}$. All of the children in TEDDY who were born between 2004 and 2010 and were followed for at least 1 year from 3 months of age $(n 7540)$ were included. Of the children, 514 were excluded from the analysis because of missing data on diabetes status of the mother ( $n$ 257), multiple births ( $n$ 252) and pre-existing type 2 diabetes in the mother ( $n$ 5), resulting in a total of 7026 children in the analysis. Of the 7026 children, $292(4 \cdot 2 \%)$ had a mother with T1D, 404 (5.8\%) had a mother with GDM, $464(6 \cdot 6 \%)$ had a mother without T1D but a father and/or sibling with T1D and 5866 (83.4\%) had no diabetes family history. Due to the small numbers, offspring with first-degree relatives with type 2 diabetes were not included in the analysis.

To assess the duration of breast-feeding and the age at introduction of new foods, families were asked to record the age at introduction of all new foods in a specific booklet that was given to the parents at study entry (TEDDY book). The TEDDY book also included information on the use of infant formulas. These records were reviewed at all clinical visits (at 3, 6, 9, 12, 18 and 24 months of age). The definition of exclusive breastfeeding included small amounts of non-nutritious drinks such as tea, water and water-based drinks, and nutritional supplements. To assess age at introduction of cow's milk, cow's milk-based infant formulas as well as partially hydrolysed infant formulas were included but extensively hydrolysed infant formulas were excluded. This definition was based on the hypothesis that cow's milk proteins may trigger islet autoimmunity ${ }^{(17)}$. The TEDDY study did not provide any recommendations or advice on infant feeding to the families.

Data on Apgar score at $5 \mathrm{~min}$ (categorized as $\geq 9$ or $<9$ ), mode of delivery (categorized as normal vaginal, caesarean section, vaginal including instruments), gestational age, birth weight, birth order (categorized as first child yes or no), maternal BMI before pregnancy (reported by the mothers), maternal age at delivery, maternal education (categorized as high school or less or more than high school) and maternal smoking during pregnancy (categorized as smoking or non-smoking) were obtained by either questionnaires or structured interviews during one of the follow-up visits in the first year of the study.

Written informed consent was obtained from the parents. The TEDDY study was approved by the ethical review board of each site.

\section{Data analysis}

Data were analysed using the statistical software package SAS version $9 \cdot 2$. Categorical variables were analysed using Pearson's $\chi^{2}$ test or Fisher's exact test. Continuous variables were tested using the $t$ test for differences in means or the Wilcoxon rank-sum test for differences in medians. Mean differences were tested using ANOVA. Data were summarized using mean and standard deviation or median and interquartile range (IQR). All tests for significance were two-tailed. Kaplan-Meier life tables were used to describe age at end of breast-feeding and age at introduction of cow's milk products and glutencontaining foods; and groups were compared using the log-rank $\chi^{2}$ statistic. Cox proportional hazard regression 
analysis was used to assess whether specific types of diabetes in the family were associated with infant feeding behaviours. The age of the child at the time when exclusive or any breast-feeding was ended or when cow's milk/gluten-containing foods were introduced was used as the time to event. We examined models with and without clinical factors (i.e. delivery mode, gestational age, Apgar score and birth weight) to determine whether they explained these associations.

\section{Results}

\section{Characteristics of the study cobort}

The proportion of infants with a 5 min APGAR score $\geq 9$, with normal vaginal delivery and who were first-born children differed by the presence of diabetes in the family member (Table 1). Also, there were differences in gestational age, birth weight, maternal BMI before pregnancy, maternal weight gain during pregnancy, maternal age at delivery and maternal education by the presence of diabetes in a family member (Table 1 ).

\section{Association of diabetes in a family member with breast-feeding bebaviour}

The initiation of breast-feeding was comparable between groups: $96 \%$ of infants with T1D mothers, $98 \%$ of infants with a father or sibling with T1D, $97 \%$ of infants with GDM mothers and $98 \%$ of infants without diabetes in the family were breast-fed during the first days of life. Univariately, exclusive breast-feeding duration was significantly shorter in offspring of mothers with T1D and GDM compared with children without diabetes in the family $(P<0 \cdot 003$, Fig. 1(a); median 0 month, IQR 0-1 months and median $0 \cdot 2$ months, IQR $0-1 \cdot 8$ months $v$. median 0.7 months, IQR $0-3.2$ months). In contrast, exclusive breast-feeding duration was significantly longer in children with a T1D father or sibling (median 0.9 months, IQR 0-4 months) compared with children without diabetes in the family (Fig. 1(a)).

The association between age at exclusive breast-feeding end and maternal T1D (hazard ratio $(\mathrm{HR})=1 \cdot 18 ; 95 \% \mathrm{CI}$ $1 \cdot 04,1 \cdot 33)$, maternal GDM $(\mathrm{HR}=1 \cdot 13 ; 95 \% \mathrm{CI} 1 \cdot 01,1 \cdot 26)$ and T1D in the father and/or sibling (HR $=0.82 ; 95 \% \mathrm{CI}$ $0 \cdot 74,0 \cdot 91)$ remained significant after adjusting for maternal smoking during pregnancy, maternal pre-pregnancy BMI, maternal weight gain during pregnancy, child's gender, maternal age, child's birth order, maternal education level and country (Model 1, Table 2). T1D in the father and/or sibling was significantly associated with later end of exclusive breast-feeding after additional adjustment for clinical factors (Model 2; HR $=0 \cdot 81 ; 95 \%$ CI 0.71, 0.92). The association between age at end of exclusive breastfeeding and maternal T1D and GDM was no longer significant after additional adjustment for clinical factors (Model 2, Table 2).

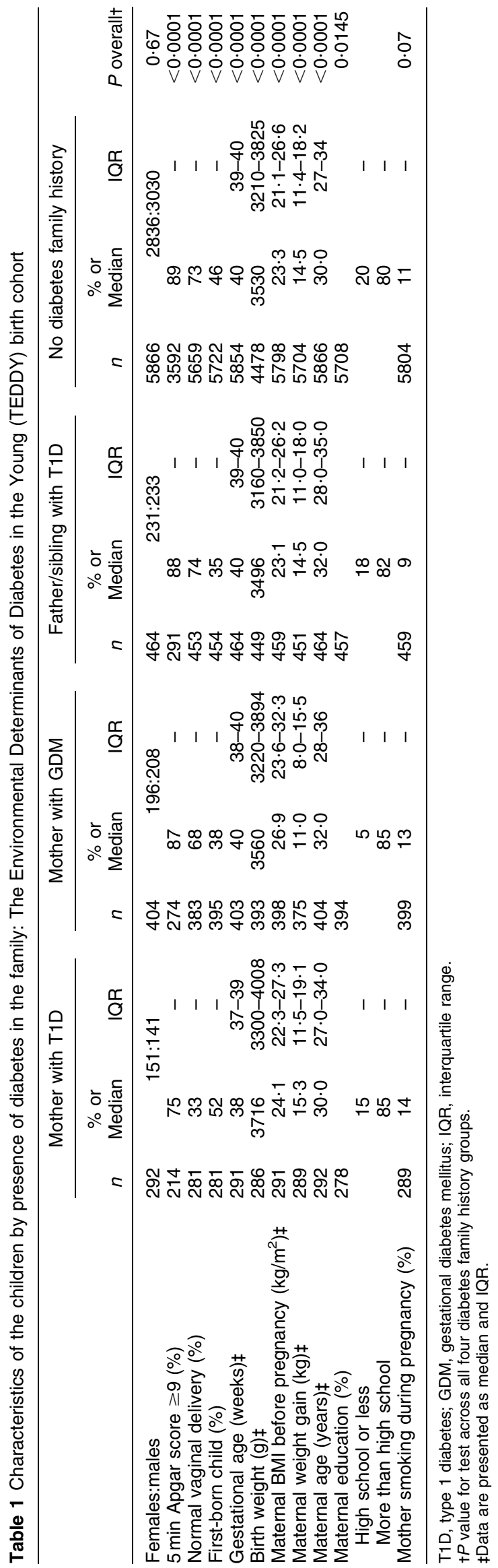


(a)

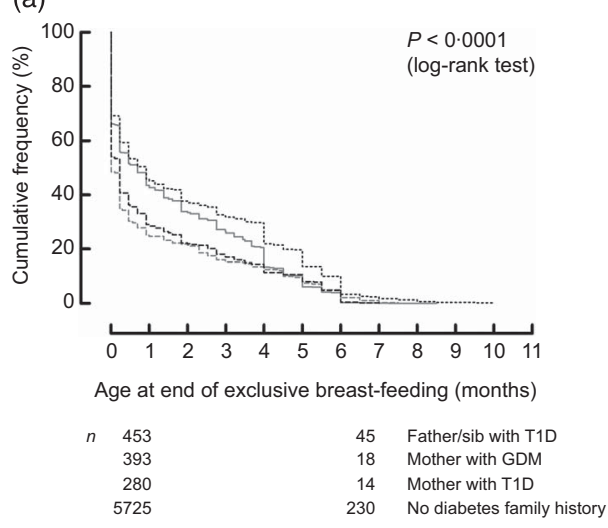

(c)



(b)

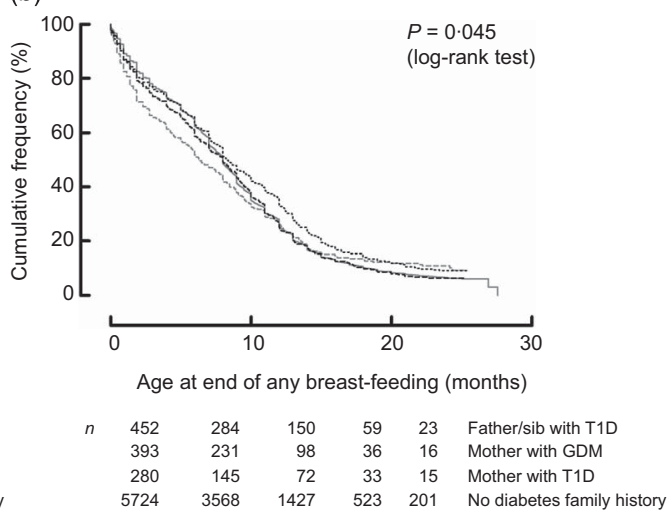

(d)



Fig. 1 Life-table analysis of age at end of exclusive breast-feeding (a), age at end of any breast-feeding (b), age at first introduction of cow's milk (c) and age at first introduction of gluten-containing cereals (d) in relation to the presence of diabetes in the family ( --_- , father/sib with T1D; - _- mother with GDM; - - , mother with T1D; _ no diabetes family history), all participating countries: The Environmental Determinants of Diabetes in the Young (TEDDY) study (sib, sibling; T1D, type 1 diabetes; GDM, gestational diabetes mellitus)

Median age at end of any breast-feeding was $6 \cdot 3$ months (IQR $1 \cdot 8-12 \cdot 1$ months) in infants with mothers with T1D, 8.0 months (IQR $2 \cdot 8-12 \cdot 0$ months) in infants with mothers with GDM, $8 \cdot 0$ months (IQR 3.8-12.0 months) in children with a T1D father and/or sibling and $8 \cdot 3$ months (IQR 3.5-13.4 months) in children without diabetes in the family (Fig. 1(b)). There were no statistically significant differences in age at end of any breast-feeding with respect to the presence of diabetes in the family after adjusting for sociodemographic (Model 1) and clinical factors (Model 2, Table 2).

Because the feeding patterns varied from country to country, we examined whether the association between the presence of diabetes in the family and feeding behaviour differed by country by testing for interaction. The association between age at end of exclusive breastfeeding and presence of diabetes in the family was clearly different in different TEDDY countries (interaction $P=0 \cdot 04$, Fig. 2). In order to explore the age at end of exclusive breast-feeding by country interaction further, multivariate models were analysed separately for the USA, Finland, Germany and Sweden (Table 3). A strong association of maternal T1D and GDM with younger age at exclusive breast-feeding end was observed in Sweden (Table 3). In the USA, exclusive and any breast-feeding end was significantly earlier in offspring of mothers with T1D (Table 3) and exclusive breast-feeding end was earlier in offspring of mothers with GDM compared with infants without presence of diabetes in the family, while exclusive breast-feeding end was later in offspring with a father and/or sibling with T1D. These associations were attenuated by adjusting for clinical factors (Table 3). In Germany and Finland, age at end of exclusive or any breast-feeding was not associated with the presence of diabetes in the family (Table 3).

\section{Association of family bistory of diabetes with the age at introduction to cow's milk and gluten-containing cereals}

The univariate analysis of the total cohort showed that offspring of mothers with T1D and GDM were introduced to cow's milk earlier (median age $0 \cdot 23$ months, IQR 0-2 months and median age $0 \cdot 23$ months, IQR $0-2 \cdot 5$ months, respectively) and infants with a father and/or sibling with T1D were introduced to cow's milk later (median age $1 \cdot 2$ months, IQR $0-5 \cdot 5$ months) compared with 


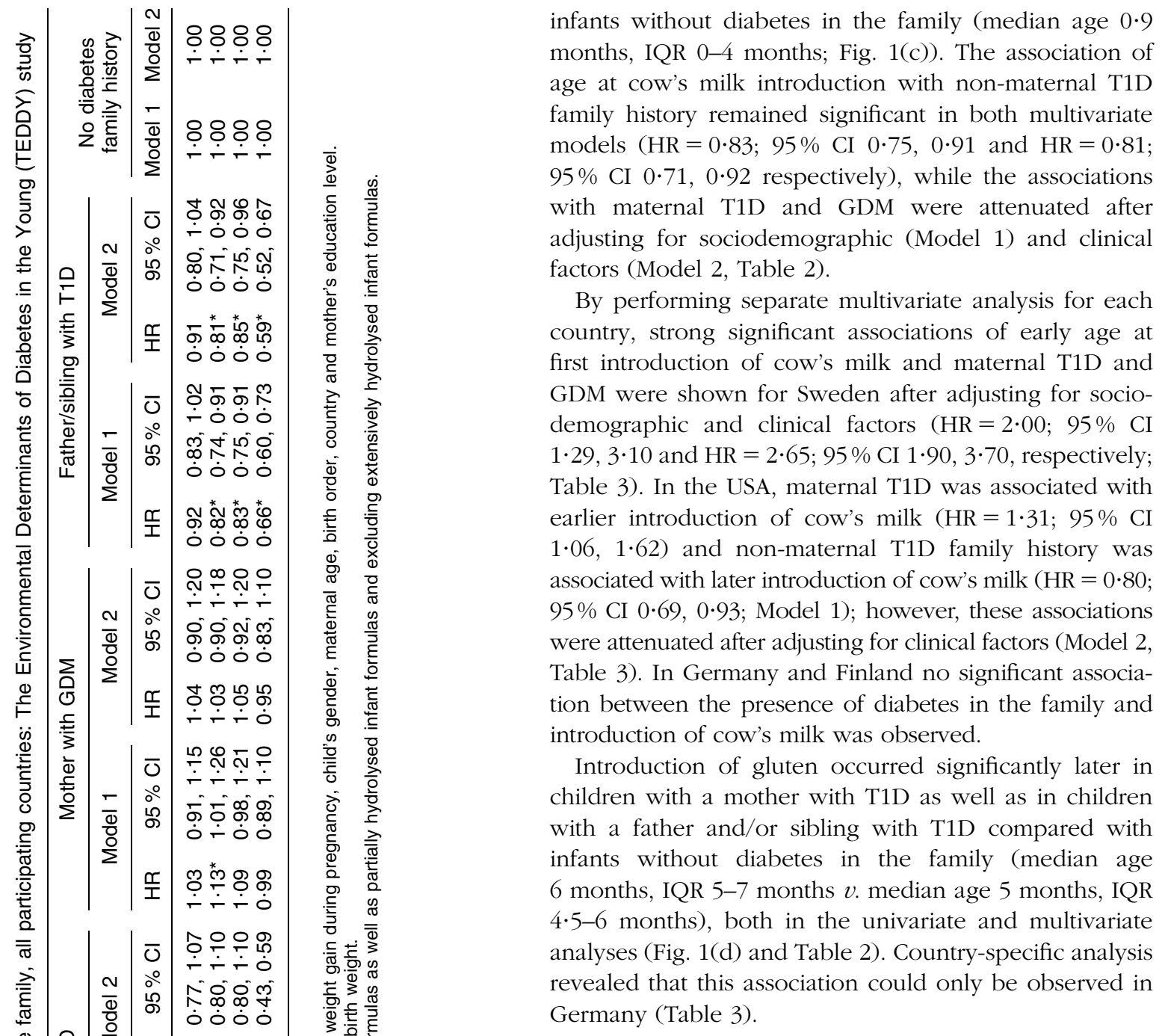

infants without diabetes in the family (median age 0.9 months, IQR 0-4 months; Fig. 1(c)). The association of age at cow's milk introduction with non-maternal T1D family history remained significant in both multivariate models $(\mathrm{HR}=0.83$; $95 \% \mathrm{CI} 0.75,0.91$ and $\mathrm{HR}=0.81$; adjusting for sociodemographic (Model 1) and clinical factors (Model 2, Table 2).

By performing separate multivariate analysis for each first introduction of cow's milk and maternal T1D and GDM were shown for Sweden after adjusting for sociodemographic and clinical factors $(\mathrm{HR}=2 \cdot 00 ; 95 \% \mathrm{CI}$ $1 \cdot 29,3 \cdot 10$ and $\mathrm{HR}=2 \cdot 65 ; 95 \%$ CI $1 \cdot 90,3 \cdot 70$, respectively; Table 3). In the USA, maternal T1D was associated with earlier introduction of cow's milk $(\mathrm{HR}=1 \cdot 31 ; 95 \% \mathrm{CI}$ $1 \cdot 06,1 \cdot 62)$ and non-maternal T1D family history was associated with later introduction of cow's milk ( $\mathrm{HR}=0 \cdot 80$; were attenuated after adjusting for clinical factors (Model 2, Table 3). In Germany and Finland no significant associathe presence of diabetes in the family and

children with a mother with T1D as well as in children with a father and/or sibling with T1D compared with infants without diabetes in the family (median age 6 months, IQR $5-7$ months $v$. median age 5 months, IQR $4 \cdot 5-6$ months), both in the univariate and multivariate revealed that this association could only be observed in Germany (Table 3).

\section{Discussion}

Our study confirms previous findings of an association between shorter exclusive breast-feeding duration and maternal T1D or GDM that can mainly be explained by demographic and clinical confounding variables ${ }^{(5-8)}$. Due to the shorter exclusive breast-feeding duration, offspring of mothers with diabetes were exposed to cow's milk earlier compared with infants without diabetes in the family. Our observations are not consistent with previous studies that reported no effect of maternal T1D on exclusive breast-feeding duration ${ }^{(9,10)}$. It is likely that the inconsistencies between the above-mentioned studies ${ }^{(5-10)}$ are resulting from different strategies in the assessment of breast-feeding habits, a large variation in numbers of children included in the studies and different infant feeding cultures. The TEDDY study provides the possibility to fill these gaps: the TEDDY study is a multinational, epidemiological study following prospectively an adequate number of children with a family history of diabetes. Within the TEDDY study, an extensive amount of dietary, 

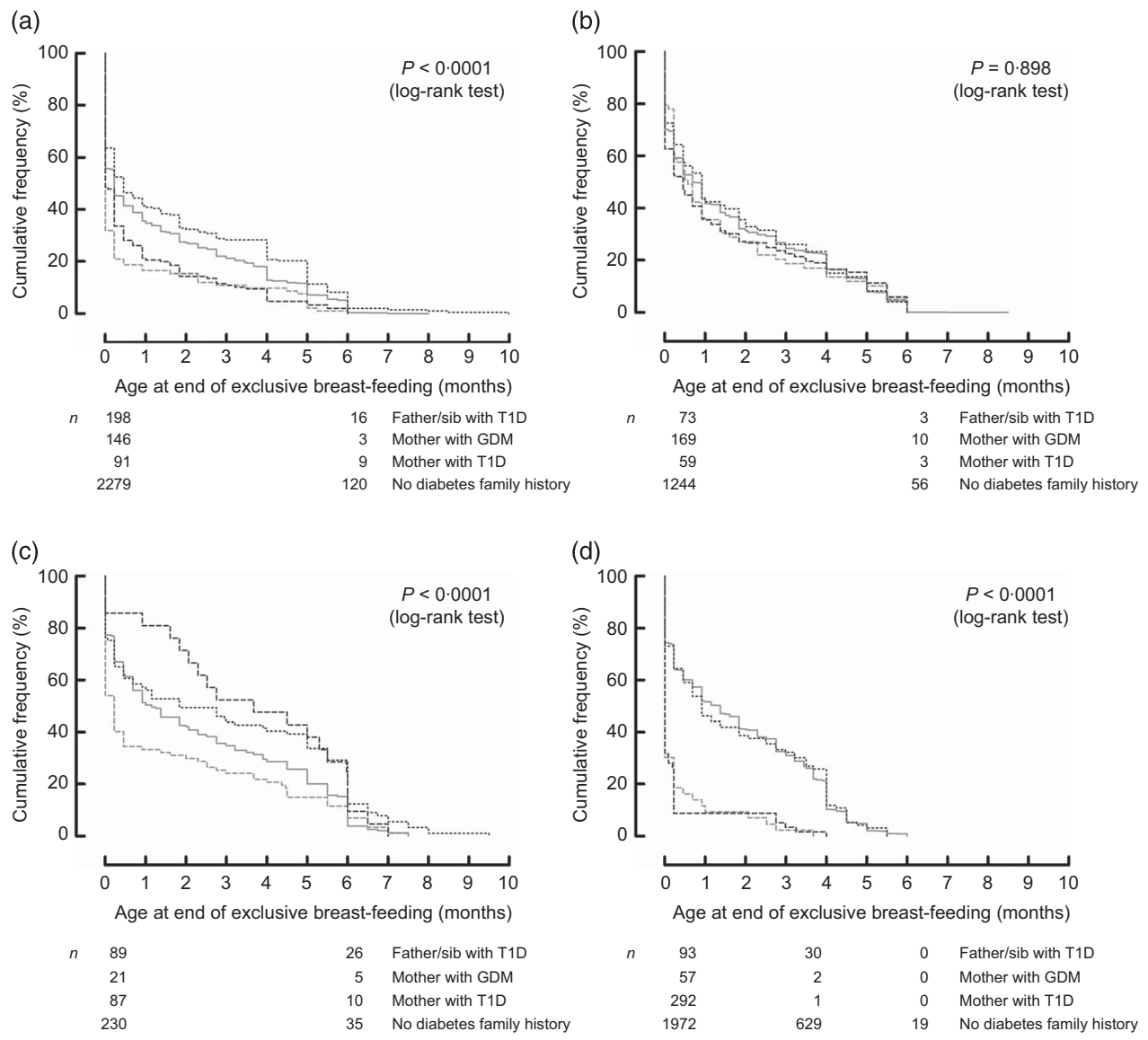

Fig. 2 Country-specific life-table analysis of age at end of exclusive breast-feeding in infants from the USA (a), Finland (b), Germany (c) and Sweden (d) in relation to the presence of diabetes in the family ( - - - - , father/sib with T1D; - - - , mother with GDM; --- , mother with T1D; , no diabetes family history): The Environmental Determinants of Diabetes in the Young (TEDDY) study (sib, sibling; T1D, type 1 diabetes; GDM, gestational diabetes mellitus)

sociodemographic and clinical data are collected according to a harmonized study protocol, enabling between-country comparisons. Furthermore, due to the prospective study design and the frequent data collection, recall bias in questionnaires addressing infant diet is minimized.

Although exclusive breast-feeding duration in infants without diabetes in the family was shorter than recommended by the WHO, the duration of exclusive breastfeeding was even shorter in infants of mothers with T1D and GDM. Our finding that this association is attenuated after adjusting for clinical factors is consistent with previous findings from studies in offspring of mothers with diabetes ${ }^{(7,8)}$. In contrast, age at end of any breastfeeding was not associated with maternal diabetes when analysing data of the total cohort. We further identified that the association between diabetes exposure in the mother and shorter exclusive breast-feeding duration differs strongly between countries. Sweden showed the strongest associations that remained significant after adjusting for sociodemographic and clinical factors. This finding does not confirm results from a recently published Swedish study claiming that factors that are associated with maternal diabetes, such as problems with establishing breast-feeding early postpartum due to the higher degree of maternal and neonatal complications, affect breast-feeding duration ${ }^{(7)}$. The inconsistency between the two studies may be due to different analytical approaches.

In the USA the associations between infant diet and maternal diabetes were attenuated after adjusting for clinical factors, indicating that in the USA maternal and neonatal complications that are associated with maternal diabetes mainly affect breast-feeding behaviour. The country-specific differences in the effect of maternal diabetes on exclusive breast-feeding behaviour were most apparent between Finland and Sweden, both countries located in the northern part of Europe and following comparable numbers of TEDDY children. Compared with Sweden, diabetes in the family was not associated with breast-feeding duration in Finland. This finding suggests that country-specific guidelines affect breast-feeding behaviour in mothers with diabetes. In our study, the definition of exclusive breast-feeding included mother's own breast milk or banked breast milk. Compared with the other countries, in Finland banked breast milk is given more commonly in hospitals 
Table 3 Country-specific analysis of infant feeding patterns in relation to the presence of diabetes in the family: The Environmental Determinants of Diabetes in the Young (TEDDY) study

\begin{tabular}{|c|c|c|c|c|c|c|c|c|c|c|c|c|c|c|}
\hline \multirow[b]{3}{*}{ Outcome } & \multicolumn{4}{|c|}{ Mother with T1D } & \multicolumn{4}{|c|}{ Mother with GDM } & \multicolumn{4}{|c|}{ Father/sibling with T1D } & \multirow{2}{*}{\multicolumn{2}{|c|}{$\begin{array}{l}\text { No diabetes } \\
\text { family history }\end{array}$}} \\
\hline & \multicolumn{2}{|c|}{ Model 1} & \multicolumn{2}{|c|}{ Model 2} & \multicolumn{2}{|c|}{ Model 1} & \multicolumn{2}{|c|}{ Model 2} & \multicolumn{2}{|c|}{ Model 1} & \multicolumn{2}{|c|}{ Model 2} & & \\
\hline & $\mathrm{HR}$ & $95 \% \mathrm{Cl}$ & $\mathrm{HR}$ & $95 \% \mathrm{Cl}$ & HR & $95 \% \mathrm{Cl}$ & HR & $95 \% \mathrm{Cl}$ & HR & $95 \% \mathrm{Cl}$ & HR & $95 \% \mathrm{Cl}$ & Model 1 & Model 2 \\
\hline USA & \multicolumn{4}{|c|}{ n 101} & \multicolumn{4}{|c|}{ n 155} & \multicolumn{4}{|c|}{ n 209} & \multicolumn{2}{|c|}{$n 2394$} \\
\hline Age at end of any breast-feeding & $1 \cdot 33^{*}$ & $1 \cdot 05,1 \cdot 69$ & 0.91 & $0.77,1.07$ & $1 \cdot 13$ & $0.92,1.38$ & $1 \cdot 38$ & $0.92,2.08$ & 0.94 & $0 \cdot 80,1 \cdot 11$ & 0.99 & $0 \cdot 76,1 \cdot 32$ & $1 \cdot 00$ & 1.00 \\
\hline Age at end of exclusive breast-feeding & $1 \cdot 43^{*}$ & $1 \cdot 14,1 \cdot 79$ & 0.94 & $0 \cdot 80,1 \cdot 10$ & $1 \cdot 21^{*}$ & $1 \cdot 0,1 \cdot 46$ & $1 \cdot 01$ & $0 \cdot 68,1.49$ & $0 \cdot 84^{*}$ & $0 \cdot 72,0.98$ & 0.94 & $0 \cdot 72,1 \cdot 22$ & $1 \cdot 00$ & $1 \cdot 00$ \\
\hline Age at introduction of cow's milk & $1 \cdot 31^{*}$ & $1 \cdot 06,1 \cdot 62$ & 0.94 & $0 \cdot 80,1 \cdot 10$ & $1 \cdot 16$ & $0 \cdot 96,1 \cdot 39$ & $1 \cdot 18$ & $0 \cdot 81,1 \cdot 73$ & $0 \cdot 80^{*}$ & $0.69,0.93$ & $0 \cdot 91$ & $0 \cdot 70,1 \cdot 17$ & 1.00 & $1 \cdot 00$ \\
\hline Age at introduction of gluten-containing cereals & 0.96 & $0 \cdot 78,1 \cdot 18$ & $0.50^{*}$ & $0.43,0.59$ & $1 \cdot 12$ & $0.93,1 \cdot 34$ & $1 \cdot 0$ & $0.69,1.45$ & 0.97 & $0 \cdot 83,1 \cdot 12$ & $1 \cdot 02$ & $0.79,1.31$ & $1 \cdot 00$ & $1 \cdot 00$ \\
\hline Finland & \multicolumn{4}{|c|}{$n 59$} & \multicolumn{4}{|c|}{$n 169$} & \multicolumn{4}{|c|}{$n 73$} & \multicolumn{2}{|c|}{ n 1246} \\
\hline Age at end of any breast-feeding & 0.84 & $0 \cdot 63,1 \cdot 12$ & $0 \cdot 85$ & $0.60,1 \cdot 19$ & 0.98 & $0 \cdot 82,1 \cdot 17$ & $1 \cdot 01$ & $0 \cdot 84,1 \cdot 22$ & $0 \cdot 81$ & $0.63,1.05$ & 0.82 & $0.63,1.07$ & $1 \cdot 00$ & 1.00 \\
\hline Age at end of exclusive breast-feeding & 0.99 & $0 \cdot 76,1 \cdot 30$ & $0 \cdot 83$ & $0 \cdot 61,1 \cdot 15$ & 1.02 & $0 \cdot 86,1 \cdot 21$ & 0.98 & $0 \cdot 82,1 \cdot 18$ & 1.02 & $0 \cdot 80,1 \cdot 30$ & 0.99 & $0 \cdot 77,1 \cdot 26$ & $1 \cdot 00$ & $1 \cdot 00$ \\
\hline Age at introduction of cow's milk & $1 \cdot 01$ & $0 \cdot 77,1 \cdot 32$ & $0 \cdot 84$ & $0 \cdot 61,1 \cdot 17$ & $1 \cdot 06$ & $0 \cdot 89,1 \cdot 26$ & $1 \cdot 05$ & $0 \cdot 88,1 \cdot 26$ & 0.95 & $0 \cdot 75,1 \cdot 21$ & 0.94 & $0 \cdot 73,1 \cdot 20$ & $1 \cdot 00$ & $1 \cdot 00$ \\
\hline Age at introduction of gluten-containing cereals & 0.85 & $0 \cdot 65,1 \cdot 11$ & 0.84 & $0.61,1 \cdot 16$ & 0.92 & $0 \cdot 77,1 \cdot 10$ & 0.94 & $0 \cdot 78,1 \cdot 13$ & 0.99 & $0 \cdot 78,1 \cdot 27$ & 0.98 & $0.76,1 \cdot 25$ & $1 \cdot 00$ & $1 \cdot 00$ \\
\hline Germany & \multicolumn{4}{|c|}{$n 89$} & \multicolumn{4}{|c|}{$n 23$} & \multicolumn{4}{|c|}{$n 89$} & \multicolumn{2}{|c|}{$n 242$} \\
\hline Age at end of any breast-feeding & $0 \cdot 86$ & $0 \cdot 65,1 \cdot 13$ & $0 \cdot 72$ & $0.53,1 \cdot 61$ & 1.06 & $0 \cdot 65,1 \cdot 73$ & 0.95 & $0.56,1 \cdot 61$ & $0 \cdot 81$ & $0 \cdot 61,1 \cdot 07$ & $0 \cdot 89$ & $0 \cdot 67,1 \cdot 18$ & $1 \cdot 00$ & 1.00 \\
\hline Age at end of exclusive breast-feeding & $1 \cdot 25$ & $0.97,1.61$ & 1.08 & $0 \cdot 80,1 \cdot 45$ & 0.76 & $0 \cdot 48,1 \cdot 22$ & $0 \cdot 71$ & $0 \cdot 43,1 \cdot 18$ & $0 \cdot 80$ & $0 \cdot 61,1 \cdot 04$ & $0 \cdot 77$ & $0.59,1.02$ & $1 \cdot 00$ & $1 \cdot 00$ \\
\hline Age at introduction of cow's milk & $1 \cdot 08$ & $0 \cdot 84,1 \cdot 39$ & 0.93 & $0.69,1 \cdot 24$ & 0.65 & $0 \cdot 41,1 \cdot 03$ & $0 \cdot 58^{\star}$ & $0.35,0.95$ & $0 \cdot 77$ & $0 \cdot 59,1 \cdot 00$ & $0 \cdot 74^{*}$ & $0.56,0.98$ & $1 \cdot 00$ & $1 \cdot 00$ \\
\hline Age at introduction of gluten-containing cereals & $0 \cdot 56^{\star}$ & $0.43,0.73$ & $0 \cdot 56^{\star}$ & $0 \cdot 42,0 \cdot 76$ & $1 \cdot 41$ & $0 \cdot 89,2 \cdot 21$ & $1 \cdot 31$ & $0 \cdot 81,2 \cdot 12$ & $0 \cdot 49^{*}$ & $0.37,0.65$ & $0.49^{*}$ & $0.37,0.65$ & 1.00 & $1 \cdot 00$ \\
\hline Sweden & \multicolumn{4}{|c|}{$n 43$} & \multicolumn{4}{|c|}{$n 57$} & \multicolumn{4}{|c|}{$n 93$} & \multicolumn{2}{|c|}{$n 1984$} \\
\hline Age at end of any & 0.90 & $0 \cdot 64,1 \cdot 26$ & 0.97 & $0.62,1.54$ & 0.93 & $0 \cdot 69,1 \cdot 24$ & $0 \cdot 85$ & $0 \cdot 60,1 \cdot 21$ & 1.03 & $0 \cdot 83,1 \cdot 30$ & 0.87 & $0 \cdot 65,1 \cdot 15$ & $1 \cdot 00$ & $1 \cdot 00$ \\
\hline Age at end of exclusive breast-feeding & $2 \cdot 69^{*}$ & $1.95,3 \cdot 73$ & $2 \cdot 60^{*}$ & $1 \cdot 67,4 \cdot 02$ & $2 \cdot 72^{*}$ & $2 \cdot 06,3.59$ & $2 \cdot 80^{*}$ & $2 \cdot 01,3 \cdot 91$ & $1 \cdot 04$ & $0 \cdot 84,1 \cdot 29$ & 0.99 & $0 \cdot 76,1 \cdot 30$ & 1.00 & $1 \cdot 00$ \\
\hline Age at introduction of cow's milk & $2 \cdot 13^{*}$ & $1 \cdot 54,2 \cdot 95$ & $2 \cdot 00^{*}$ & $1 \cdot 29,3 \cdot 10$ & $2 \cdot 51^{*}$ & $1 \cdot 90,3 \cdot 31$ & $2 \cdot 65^{\star}$ & $1 \cdot 90,3 \cdot 70$ & $1 \cdot 10$ & $0 \cdot 88,1 \cdot 36$ & 1.06 & $0.81,1 \cdot 39$ & $1 \cdot 00$ & $1 \cdot 00$ \\
\hline Age at introduction of gluten-containing cereals & $1 \cdot 02$ & $0 \cdot 74,1 \cdot 41$ & 0.91 & $0.59,1 \cdot 40$ & 0.99 & $0 \cdot 75,1 \cdot 31$ & $1 \cdot 04$ & $0 \cdot 75,1 \cdot 44$ & 0.98 & $0 \cdot 79,1 \cdot 22$ & 0.99 & $0 \cdot 76,1 \cdot 29$ & $1 \cdot 00$ & $1 \cdot 00$ \\
\hline
\end{tabular}

T1D, type 1 diabetes; GDM, gestational diabetes mellitus; HR, hazard ratio.

Model 1: adjusted for mother's smoking status, mother's pre-pregnancy BMI, mother's weight gain during pregnancy, child's gender, maternal age, birth order and mother's education level.

Model 2: Model 1 plus adjustment for delivery mode, gestational age, Apgar score and birth weight.

Introduction of cow's milk is defined as cow's milk including cow's milk-based infant formulas as well as partially hydrolysed infant formulas and excluding extensively hydrolysed infant formula.

${ }^{*}$ Significant at the $P<0.05$ level. 
to newborn infants of mothers who are not able to successfully breast-feed their infants ${ }^{(18)}$. In contrast, in Sweden offspring of mothers with diabetes are given more commonly infant formula during the first days of life to avoid hypoglycaemia (C Andrén Aronsson, personal communication, March 2012). We hypothesize that these different neonatal feeding guidelines/practices may be the cause for the observed country-specific differences. We did further observe that ignoring infant formula supplementation during the first week of life when defining age at end of exclusive breast-feeding did not change the reported association of earlier end of exclusive breast-feeding and maternal T1D or GDM (data not shown). This observation strengthens the hypothesis that supplementation of infant formula during the first days of life results in the earlier end of exclusive breast-feeding in offspring of Swedish mothers with diabetes.

In contrast to previous studies, the current study furthers our knowledge on infant feeding patterns by evaluating infants with a mother without diabetes but another first-degree relative with T1D and comparing them to infants without a diabetes history in the family. We observed that in infants with a father and/or sibling with T1D, end of breast-feeding and first exposure to cow's milk and gluten-containing cereals occurred later compared with infants without diabetes in the family. These associations remained significant after adjusting for confounders, indicating that the observed infant feeding patterns are independent of sociodemographic and clinical factors. All families who are participating in TEDDY were informed about the increased T1D risk in their offspring, which is tenfold higher in offspring with a first-degree relative with T1D. Families who are aware of the increased diabetes risk in their offspring are known to modify their behaviour, including feeding patterns, with the aim to prevent disease ${ }^{(19)}$, although families did not receive any specific recommendations on infant diet by the TEDDY study. Furthermore, in none of the participating TEDDY countries are families with diabetes given specific infant feeding recommendations by health-care providers. Among the countries participating in TEDDY, Finland, Germany and parts of the USA have been participating in dietary intervention trials to prevent islet autoimmunity and T1D in high-risk children by delaying introduction of cow's milk ${ }^{(20)}$ or gluten ${ }^{(21)}$. Families with the presence of T1D in the family may have known about these intervention strategies and implemented them in infant diet. We hypothesize that due to the difficulties in breast-feeding that are encountered by mothers with T1D, a longer breast-feeding duration and later exposure to cow's milk could only be observed in infants with a father or sibling with T1D. The fact that first exposure to glutencontaining cereals, a feeding pattern which, compared to cow's milk introduction, is not associated with successful breast-feeding, was delayed in offspring of mothers with
T1D as well as in infants with a father or sibling with T1D further strengthens this hypothesis.

The association between delayed gluten introduction in German offspring with a first-degree relative with T1D is probably due to the fact that the BABYDIET study, a dietary intervention study applying delayed gluten exposure, was performed only in Germany where newborns with T1D in a first-degree relative were recruited between 2001 and $2004^{(21)}$.

In conclusion, our results show that diabetes in the family influences the duration of exclusive breast-feeding, age at introduction of cow's milk and age at introduction of gluten-containing cereals. The finding that neonatal complications are strongly affecting exclusive breastfeeding behaviour in offspring of mothers with diabetes needs to be considered when developing strategies to improve breast-feeding behaviour in mothers with diabetes and strategies to prevent disease.

These associations, however, clearly differ by country, indicating that country-specific recommendations on infant feeding and guidelines on neonatal care in offspring of mothers with diabetes strongly influence infant feeding patterns. This may also explain inconsistencies in findings between previous studies in this field.

\section{Acknowledgements}

Sources of funding: The TEDDY study is funded by grant numbers DK 63829, 63861, 63821, 63865, 63863, 63836, 63790 and UC4DK095300 and contract number HHSN267200700014C from the National Institute of Diabetes and Digestive and Kidney Diseases (NIDDK), the National Institute of Allergy and Infectious Diseases (NIAID), the National Institute of Child Health and Human Development (NICHD), the National Institute of Environmental Health Sciences (NIEHS), the Juvenile Diabetes Research Foundation (JDRF) and the Centers for Disease Control and Prevention (CDC). The NIDDK, NIAID, NICHD, NIEHS, JDRF and CDC had no role in the design, analysis or writing of this article. Conflicts of interest: There are no conflicts of interest. Authors' contributions: S.H. designed the study, interpreted data and wrote the manuscript. K.V. and W.M. performed analysis of data and contributed to interpretation of data. C.A.A., N.F. and P.G. contributed to acquisition of data and provided input to interpretation of data. U.U. and J.Y. provided input to the analysis and interpretation of data and revised the article critically. J.M.N. and S.M.V. provided major input to the study design and analysis and interpretation of data, contributed to writing and revised the article critically. J.M.N and S.M.V. are sharing last authorship. Acknowledgements: The authors express their gratitude to the children and parents who participated, and wish to thank the TEDDY staff for excellent collaboration over the years. 


\section{References}

1. Dewey KG, Heinig MJ, Nommsen LA et al. (1992) Growth of breast-fed and formula-fed infants from 0 to 18 months: the DARLING Study. Pediatrics 89, 1035-1041.

2. World Health Organization (2002) Infant and young child nutrition. Global strategy on infant and young child feeding http://apps.who.int/gb/archive/pdf_files/WHA55/ea5515.pdf (accessed October 2011).

3. UNICEF (2009) Infant and young child feeding (2000-2007). http://www.childinfo.org/breastfeeding_countrydata.php (accessed October 2011).

4. Scott JA \& Binns CW (1999) Factors associated with the initiation and duration of breastfeeding: a review of the literature. Breastfeed Rev 7, 5-16.

5. Hummel S, Winkler C, Schoen S et al. (2007) Breast-feeding habits in families with type 1 diabetes. Diabet Med $\mathbf{2 4}$, 671-676.

6. Hummel S, Knopff A, Hummel M et al. (2008) Breastfeeding in woman with gestational diabetes. Dtsch Med Wochenstr 133, 180-184.

7. Sparud-Lundin C, Wennergren M, Elfvin A et al. (2011) Breastfeeding in women with type 1 diabetes: exploration of predictive factors. Diabetes Care 34, 296-301.

8. Sorkio S, Cuthbertson D, Bärlund S et al. (2010) Breastfeeding patterns of mothers with type 1 diabetes: results from an infant feeding trial. Diabetes Metab Res Rev 26, 206-211.

9. Webster J, Moore K \& McMullan A (1995) Breastfeeding outcomes for women with insulin dependent diabetes. J Hum Lact 11, 195-200.

10. Stage E, Norgard H, Damm P et al. (2006) Long-term breastfeeding in women with type 1 diabetes. Diabetes Care 29, 771-774.

11. Pflüger M, Winkler C, Hummel S et al. (2010) Early infant diet in children at high risk for type 1 diabetes. Horm Metab Res 42, 143-148.

12. Norris JM, Barriga K, Klingensmith G et al. (2003) Timing of initial cereal exposure in infancy and risk of islet autoimmunity. JAMA 290, 1713-1720.

13. Ziegler AG, Schmid S, Huber D et al. (2003) Early gluten exposure is a risk factor for type 1 diabetes-associated autoimmunity. JAMA 290, 1721-1728.

14. Virtanen SM, Kenward MG, Erkkola M et al. (2006) Age at introduction of new foods and advanced beta cell autoimmunity in young children with HLA-conferred susceptibility of type 1 diabetes. Diabetologia 49, 1512-1521.

15. Kimpimäki T, Erkkola M, Korhonen S et al. (2001) Shortterm exclusive breastfeeding predisposes young children with increased genetic risk of type 1 diabetes to progressive $\beta$-cell autoimmunity. Diabetologia 44, 63-69.

16. TEDDY Study Group (2008) The Environmental Determinants of Diabetes in the Young (TEDDY) Study. Ann $N Y$ Acad Sci 1150, 1-13.

17. Knip M, Virtanen SM, Seppä K et al. (2010) Dietary intervention in infancy and later signs of beta-cell autoimmunity. N Engl J Med 363, 1900-1908.

18. Erkkola M, Salmenhaara M, Kronberg-Kippilä C et al. (2010) Determinants of breast-feeding in a Finnish birth cohort. Public Health Nutr 13, 504-513.

19. Baughcum AE, Johnson SB, Carmichael SK et al. (2005) Maternal efforts to prevent type 1 diabetes in at-risk children. Diabetes Care 28, 916-921.

20. TRIGR Study Group, Akerblom HK, Krischer J, Virtanen SM et al. (2011) The Trial to Reduce IDDM in the Genetically at Risk (TRIGR) study: recruitment, intervention and followup. Diabetologia 54, 627-633.

21. Hummel S, Pflüger M, Hummel M et al. (2011) Primary dietary intervention study to reduce the risk of islet autoimmunity in children at increased risk for type 1 diabetes: the BABYDIET study. Diabetes Care 34, 1301-1305.

\section{Appendix}

\section{The Teddy Study Group}

Colorado Clinical Center

Marian Rewers, MD, PhD, Principal Investigator ${ }^{1,4,6,10,11}$; Katherine Barriga $^{12}$; Kimberly Bautista ${ }^{12}$; Judith Baxter ${ }^{9,12,15}$; George Eisenbarth, MD, PhD; Nicole Frank ${ }^{2}$; Patricia Gesualdo $^{2,6,12,14,15}$; Michelle Hoffman ${ }^{12,13,14}$; Lisa Ide; Rachel Karban ${ }^{12}$; Edwin Liu, MD ${ }^{13}$; Jill Norris, PhD ${ }^{2,12}$; Kathleen Waugh ${ }^{7,12,15}$; Adela Samper-Imaz; Andrea Steck, MD (University of Colorado, Anschutz Medical Campus, Barbara Davis Center for Childhood Diabetes).

\section{Georgia/Florida Clinical Center}

Jin-Xiong She, PhD, Principal Investigator ${ }^{\mathrm{a}, 1,3,4,11}$; Desmond Schatz, MD ${ }^{\mathrm{b}, 4,5,7,8}$; Diane Hopkins ${ }^{\mathrm{a}, 12}$; Leigh Steed $^{\mathrm{a}, 6,12,13,14,15}$; Jamie Thomas ${ }^{\mathrm{b}, 12}$; Katherine Silvis ${ }^{\mathrm{a}, 2}$; Michael Haller, MD ${ }^{\mathrm{b}, 14}$; Meena Shankar ${ }^{\mathrm{b}, 2}$; Kim English ${ }^{\mathrm{a}}$; Richard McIndoe, $\mathrm{PhD}^{\mathrm{a}}$; Haitao Liu, $\mathrm{MD}^{\mathrm{c}}$; John Nechtman $^{c}$; Joshua Williams ${ }^{\mathrm{a}}$; Gabriela Foghis ${ }^{\mathrm{a}}$; Stephen W. Anderson, $\mathrm{MD}^{\mathrm{d}}$ ( ${ }^{\mathrm{a}}$ Georgia Health Sciences University; ${ }^{\mathrm{b}}$ University of Florida; ${ }^{\mathrm{C}} \mathrm{Jinfiniti} \mathrm{Biosciences} \mathrm{LLC,} \mathrm{Augusta,}$ GA; ${ }^{\mathrm{d}}$ Pediatric Endocrine Associates, Atlanta, GA).

\section{Germany Clinical Center}

Anette G. Ziegler, MD, Principal Investigator ${ }^{\mathrm{a}, 1,3,4,11}$; Alexandra Achenbach, $\mathrm{PhD}^{\mathrm{b}, 12}$; Heike Boerschmann ${ }^{\mathrm{a}, 14}$; Ezio Bonifacio, $\mathrm{PhD}^{\mathrm{b}, 5}$; Melanie Bunk ${ }^{\mathrm{a}}$; Johannes Försch ${ }^{\mathrm{a}}$; Lydia Henneberger $^{\mathrm{a}, 2,12}$; Michael Hummel, MD ${ }^{\mathrm{a}, 13}$; Sandra Hummel, PhD ${ }^{\mathrm{a}, 2}$; Gesa Joslowski ${ }^{\mathrm{c}, 2}$; Mathilde Kersting, $\mathrm{PhD}^{\mathrm{c}, 2}$; Annette Knopff ${ }^{\mathrm{a}, 7}$; Nadja Kocher ${ }^{\mathrm{a}}$; Sibylle Koletzko, MD ${ }^{\mathrm{d}, 13}$; Stephanie Krause ${ }^{\mathrm{a}}$; Claudia Matzke ${ }^{\mathrm{a}}$; Astrid Mittermeier ${ }^{\mathrm{a}}$; Claudia Peplow ${ }^{\mathrm{b}, 12}$; Maren Pflüger ${ }^{\mathrm{a}, 6}$; Claudia Ramminger ${ }^{\mathrm{a}}$; Elisabeth Strauss ${ }^{\mathrm{a}}$; Sargol Rash-Sur ${ }^{\mathrm{a}}$; Roswith Roth, PhD ${ }^{\mathrm{a}, 9}$; Julia Schenkel ${ }^{\mathrm{a}}$; Joanna Stock ${ }^{\mathrm{a}}$; Katja Voit ${ }^{\mathrm{a}}$; Christiane Winkler, PhD ${ }^{\mathrm{a}, 2,12,15}$; Anja Wosch ${ }^{\mathrm{a}}$ ( ${ }^{\mathrm{a}}$ Forschergruppe Diabetes $\mathrm{eV}$ at Helmholtz Zentrum München; ${ }^{\mathrm{b} C e n t e r}$ for Regenerative Therapies, TU Dresden; 'Dr von Hauner Children's Hospital, Department of Gastroenterology, Ludwig Maximillians University Munich; ${ }^{\mathrm{d}}$ Research Institute for Child Nutrition, Dortmund).

\section{Finland Clinical Center}

Olli G. Simell, MD, PhD, Principal Investigator ${ }^{\mathrm{a}, \mathrm{b}, 1,4,11,13}$; Heikki Hyöty, MD, PhD ${ }^{\mathrm{c}, \mathrm{d}, 6}$; Jorma Ilonen, $\mathrm{MD}, \mathrm{PhD}^{\mathrm{a}, \mathrm{e}, 3}$; Mikael Knip, MD, $\mathrm{PhD}^{\mathrm{c}, \mathrm{d}}$; Maria Lönnrot, MD, $\mathrm{PhD}^{\mathrm{c}, \mathrm{d}, 6}$; Elina Mäntymäaki ${ }^{\mathrm{a}, \mathrm{b}}$; Juha Mykkänen, $\mathrm{PhD}^{\mathrm{a}, \mathrm{b}}$; Kirsti Näntö-Salonen, MD, $\mathrm{PhD}^{\mathrm{a}, \mathrm{b}, 12}$; Tiina Niininen ${ }^{\mathrm{c}, \mathrm{d}}$; Mia Nyblom $^{\mathrm{c}, \mathrm{d}}$; Anne Riikonen ${ }^{\mathrm{c}, \mathrm{d}, 2}$; Minna Romo ${ }^{\mathrm{a}, \mathrm{b}}$; Barbara Simell ${ }^{\mathrm{a}, \mathrm{b}, 12,15}$; Tuula Simell, PhD ${ }^{\mathrm{a}, \mathrm{b}, 9,12}$; Ville Simell ${ }^{\mathrm{a}, \mathrm{b}, 13}$; Maija Sjöberg ${ }^{\mathrm{a}, \mathrm{b}, 12,14}$; Aino Stenius ${ }^{\mathrm{f}, \mathrm{g}}$; Eeva Varjonen ${ }^{\mathrm{a}, \mathrm{b}}$; Riitta Veijola, MD, PhD ${ }^{\mathrm{f}, \mathrm{g}}$; Suvi M. Virtanen, MD, $\mathrm{PhD}^{\mathrm{c}, \mathrm{d}, \mathrm{h}, 2}$ ( ${ }^{\mathrm{a} U n i v e r s i t y}$ of Turku; ${ }^{\mathrm{b}}$ Turku University Hospital; ${ }^{\mathrm{c}}$ University of Tampere; ${ }^{\mathrm{d}}$ Tampere University Hospital; ${ }^{\mathrm{e}}$ University of Kuopio; ${ }^{\mathrm{f}}$ University of Oulu; ${ }^{\mathrm{g}}$ Oulu 
University Hospital; ${ }^{h}$ National Institute for Health and Welfare, Helsinki).

\section{Sweden Clinical Center}

Åke Lernmark, PhD, Principal Investigator ${ }^{1,3,4,8,10,11,15}$; Daniel Agardh, $\mathrm{MD}, \mathrm{PhD}^{13}$; Peter Almgren; Eva Andersson; Carin Andrén Aronsson ${ }^{2,13}$; Maria Ask; Ulla-Marie Karlsson; Corrado Cilio, $\mathrm{MD}, \mathrm{PhD}^{5}$; Jenny Bremer; Emilie EricsonHallström; Thomas Gard; Joanna Gerardsson; Gertie Hansson $^{12,14}$; Monica Hansen; Susanne Hyberg; Rasmus Håkansson; Fredrik Johansen; Linda Jonsson; Helena Larsson, $\mathrm{MD}, \mathrm{PhD}^{14}$; Barbro Lernmark, $\mathrm{PhD}^{9,12}$; Maria Markan; Theodosia Massadakis; Jessica Melin; Maria Månsson-Martinez; Anita Nilsson; Kobra Rahmati; Monica Sedig Järvirova; Sara Sibthorpe; Birgitta Sjöberg; Anna Skogberg; Carina Törn, $\mathrm{PhD}^{3,15}$; Anne Wallin; Åsa Wimar; Sofie Åberg (Lund University).

\section{Washington Clinical Center}

William A. Hagopian, MD, PhD, Principal Investigator $^{1,3,4,5,6,7,11,13,14}$; Xiang Yan, MD; Michael Killian ${ }^{6,7,12,13}$; Claire Cowen Crouch ${ }^{12,14,15}$; Kristen M. Hay ${ }^{2}$; Stephen Ayres; Carissa Adams; Brandi Bratrude; David Coughlin; Greer Fowler; Czarina Franco; Carla Hammar; Diana Heaney; Patrick Marcus; Arlene Meyer; Denise Mulenga; Elizabeth Scott; Jennifer Skidmore; Joshua Stabbert; Viktoria Stepitova; Nancy Williams (Pacific Northwest Diabetes Research Institute).

\section{Pennsylvania Satellite Center}

Dorothy Becker, MD; Margaret Franciscus ${ }^{12}$; MaryEllen Dalmagro-Elias ${ }^{2}$; Ashi Daftary, MD (Children's Hospital of Pittsburgh, University of Pittsburgh Medical Center).

\section{Data Coordinating Center}

Jeffrey P. Krischer, PhD, Principal Investigator ${ }^{1,4,5,10,11}$; Michael Abbondondolo; Lori Ballard ${ }^{3,9,14,15}$; Rasheedah Brown ${ }^{12,15}$; Brant Burkhardt, $\mathrm{PhD}^{5,6}$; David Cuthbertson; Christopher Eberhard; Steven Fiske; Veena Gowda; David Hadley, PhD; Hye-Seung Lee, $\mathrm{PhD}^{3,6,13,15}$; Shu Liu; Kristian Lynch, $\mathrm{PhD}^{9}$; Jamie Malloy; Cristina McCarthy $^{12,15}$; Wendy McLeod ${ }^{2,5,6,13,15}$; Laura Smith, $\mathrm{PhD}^{9}$; Susan Smith ${ }^{12,15}$; Ulla Uusitalo, $\mathrm{PhD}^{2,15}$; Kendra Vehik, $\mathrm{PhD}^{4,5,9,14,15}$; Earnest Washington; Jimin Yang, $\mathrm{PhD}, \mathrm{RD}^{2,15}$ (University of South Florida).

\section{Project Scientist}

Beena Akolkar, PhD $1,3,4,5,7,10,11$ (National Institute of Diabetes and Digestive and Kidney Diseases).

\section{Other contributors}

Kasia Bourcier, $\mathrm{PhD}^{\mathrm{a}, 5}$; Thomas Briese, $\mathrm{PhD}^{\mathrm{b}, 6,15}$; Henry Erlich, $\mathrm{PhD}^{\mathrm{c}, 3}$; Suzanne Bennett Johnson, $\mathrm{PhD}^{\mathrm{d}, 9,12}$; Steve Oberste, $\mathrm{PhD}^{\mathrm{e}, 6}$ ( ${ }^{\mathrm{a}}$ National Institute of Allergy and Infectious Diseases; ${ }^{\mathrm{b}}$ Columbia University; 'Children's Hospital Oakland Research Institute; ${ }^{\mathrm{d}}$ Florida State University; ${ }^{\mathrm{e}}$ Centers for Disease Control and Prevention).

\section{Committees}

${ }^{1}$ Ancillary Studies; ${ }^{2}$ Diet; ${ }^{3}$ Genetics; ${ }^{4}$ Human Subjects/ Publicity/Publications; ${ }^{5}$ Immune Markers; ${ }^{6}$ Infectious Agents; ${ }^{7}$ Laboratory Implementation; ${ }^{8}$ Maternal Studies; ${ }^{9}$ Psychosocial; ${ }^{10}$ Quality Assurance; ${ }^{11}$ Steering; ${ }^{12}$ Study Coordinators; ${ }^{13}$ Celiac Disease; ${ }^{14}$ Clinical Implementation; ${ }^{15}$ Quality Assurance Subcommittee on Data Quality. 